of reptiles to the flexible type of mammals. The evidence available did not support the view that hairs were directly homologous with reptilian prototrichs; the hair follicles were probably entirely new structures which arose in the epidermis adjacent to reptilian-like scales and not derived from any part of them. In addition to such primary follicles secondary follicles forming the underfur were later evolved, with a consequent increase in the extent of the granular layer. The close association of the hair follicles with a flexible type of stratum corneum was seen in certain aquatic species where hairs were reduced in number and a parakeratotic layer occurred. The pathological appearance of parakeratosis in mammalian epidermis might be considered a reversion to this more primitive type.

Dr. J. Cohen described his experiments on the transplantation of the end bulb of the vibrissa follicle in the rat. Such a transplant produced a succession of whiskers when implanted into spleen or ear but regrossed in the thigh. The dermal papilla, still surrounded by its matrix, produced a succession of whiskers when implanted into ear skin; the follicles of such implants were either of donor or host type, or both; this was considered to depend on the origin of the follicular cells. The matrix, when transplanted to ear skin, occasionally produced a short length of whisker shaft, but usually keratinized without further growth, with a scatter of its melanocytes. The dermal papilla alone produced no whisker and was not 'visible' at biopsy after more than two weeks; before this it became invested in local epidermis and it was presumed that it initiated hair growth of local type. Dermal papillæ might produce whiskers or seales when transplanted to the tail. It was presumed that whiskers were produced from 'dirty' papillæ, that is, papillæ with adherent epidermal cells.

The cyclic activity of hair follicles was discussed by Dr. F. J. Ebling and Dr. E. Johnson. Dr. Johnson opened by describing the waves of hair growth throughout life in a colony of albino rats. Hair first erupted from dorsal follicles at 5 days of age and from ventral at 10 days. Hair replacement, with almost simultaneous eruption ventrally and dorsally, first occurred at 35-42 days; in subsequent activity there was an increasing lag in eruption in the back and head regions, so that a wave pattern was produced and indeed the waves came to overlap. A number of experimental treatments, for example, hypophysectomy, adrenalectomy, gonadectomy, and administration of thyroxine, advanced the start of follicular activity, and a number of others, for example, œstradiol, testosterone, ACTH, and thiouracil, retarded it. All these effects were more marked in the dorsal region than in the ventral.
CEstradiol also reduced the rate of growth of hair during the active phase and thus hair length was increased by ovariectomy or hypophysectomy. Thyroxine also slightly increased hair length in the female but not in the male. No other hormonal treatments affected hair length. Experiments on the plucking of hair to some extent supported the idea that a rhythm inherent within the follicle was due to the build-up and release of an inhibitor, since the maximum advancement of activity was secured by plucking the hair towards the end of the previous phase of growth, when any inhibitor would be at its highest concentration. But the inhibitor hypothesis would not explain why plucking early in activity did not prolong the period of growth but on the contrary induced premature transformation to the resting stage, nor why plucking just before the onset of activity actually delayed it.

Dr. Ebling continued by describing their experiments on skin grafts. In grafts rotated through $180^{\circ}$ on the flank or in transposed flaps of skin, hair follicles continued in their original rhythms, inducing the requisite vascularization during activity. But when homografts were exchanged between rats having an age difference of three weeks, follicular activity in some circumstances came into line with that of the host. Similarly, a cross-effect on follicular activity could be clearly shown in parahiotically joined rats of the same or different ages. Thus it appeared that there were transmissible systemic factors influeneing hair growth. Dr. Ebling and Dr. Johnson concluded that both an inherent rhythm, possibly involving a build up of inhibitor, and some systemic timing factor contributed to the control of follicular activity. Experimental evidence was against the idea that the wave of activity was propagated. The apparent self-wise behaviour of follicles in autografts could be reconciled with the idea of systemic timing factors by supposing that after the first wave, the reaction time of dorsal follicles became longer than that of ventral ones. There was preliminary evidence to suggest that changes took place in the dermis at the eritical time. When the events of the first wave were determined, about twelve days before eruption of hair, there was little difference between the amounts of collagen in dorsal and ventral skin. But, by the second wave, though it had increased in both regions, the dorsal skin contained much more collagen. Perhaps, therefore, differences in timing between dorsal and ventral follicles developed as a result of changes in the dermis. Such difforences could also explain the differential effect of hormonal treatments; hormones might act by modifying this dermal environment.

The full report of the synposium will he published as a memoir of the Zoological Society. F. J. EbLING

\title{
GROUND-WATER: GEOLOGICAL AND ENGINEERING ASPECTS
}

$\mathrm{U}^{\mathrm{s}}$ NDER this general title a symposium of communications was presented on February 27, at the Institution of Civil Engineers, in the course of a meeting organized jointly by the Institution of Water Engineers and the Geological Society of London. It was attended by nearly 600 people widely representative of the various interests which were associated with the meeting. Six communications were presented.

The meeting origineted from a proposal, made early in 1962 by Prof. S. E. Hollingworth (University College. London), during his presidency of the Geological Society, that a joint meeting be hold by the Society and the Institution, for the discussion of certain matters of immediate interest to both bodies, relating to the geological and engineering aspects of ground-water.

The symposium was divided into two sessions: at the first, the chair was taken by Prof. O. M. B. Bulman, president of the Geological Society, and during its course five communications were presented. At the second, $\mathrm{Mr}$. N.A.F. Rowntree, president of the Institution of Water Engineers, took the chair for the presentation of the sixth communication.

In the introductory communication, "Geology in Relation to Ground-water", Dr. S. Buchan (assistant director, Geological Survey of Great Britain, London, S.W.7), paid tribute to the pioneers, William Smith, William Whitaker, and Oscar Meinzer, who realized, respectively, the need for the stratigraphical classification of rocks, the systematic gathering of statistics relating to bore-hole yields and water-levels, and the application of the principles of hydrology to ground-water.

Buchan summed up the types of field data and tests which are needed in ground-water investigations, and the methods of analysing and applying the statistics obtained from actual observations. He referred to the attempts which have been made to draw up a 'water balance' from 
which the ground-water reserves may be assessed. This involves, of necessity, an estimate of the rainfall and of the evaporation taking place after rainfall. Here Penman's method of estimating evaporation "is almost certainly the best". More difficult, however, is the assessment of the extent of natural recharge, for example, where a stream crosses the outerop of an aquifer, especially if its absorption capacity is not great enough to receive the rainfall at all times. The 'debit' side of the water balance is made up of the amount abstracted by man, plus the discharge at the surface, to which must be added some allowance for water infiltrating below ground into other aquifers. From these calculations, the 'safe' yield of an aquifer may be made. This is the yield that may be relied on when the entire natural replenishment from rainfall is abstracted.

Engineers are further concerned by the changes in the quality of ground-water which occur during its passage through the soil and sub-soil. These changes are caused by interaction between rain-water and the organic and inorganic compounds. A further factor is that, in passing through the atmosphere, rain will dissolve gases present therein; the weak acids thus formed will form salts in the ground through which they percolate. Quartz, sand, chalk, and clay each produce their own effects on rain flowing through them; where percolation occurs through more than one geological formation, the chemical action is complicated still further. Along coastal areas, infiltration of saline water has occurred, either as a result of a sea-water 'invasion' when the land-surface was lower, or as a result of over-pumping from aquifers. Organic compounds in the soil may absorb oxygen from nitrates or from other organic substances, and may thus cause contamination by anaerobic reaction. Iron and manganese compounds may be produced in this way; other contaminating products are hydrogen sulphide and carbon dioxide. More research is needed into the influence of the soil and subsoil on pollution from surface sources; chemical and biochemical reactions and rates of movement offer scope for investigation which could result in better knowledge of the natural control of pollution.

In the next communication, entitled "Engineoring Problems of Ground-water", Mr. G. M. Swales (chief engineer, East Surrey Water Company, Redhill, Surrey) gave many practical observations arising from his own considerable experience in obtaining water from boreholes. Engineers concerned with wells can rarely see, in their natural state, the materials through which a borehole passes. Lack of exact knowledge thus leads to reliance on sampling techniques. The smallness of the area of a borehole in plan makes it difficult to decide its best location accurately, even when making use of very detailed geological information and maps. There are, however, basic differences between consolidated and unconsolidated ground, the effects of which are to make it relatively difficult to site a borehole in the former, but easy to construct one; whoreas in unconsolidated ground the converse is the case. To overcome these difficulties, trial borings are often made before any major work proceeds. Such trial borings must be done with great care and thoroughness; great care is ealled for in analysing the results, both of yield and of borehole samples, accurately located and examined.

Boring in unconsolidated strata provides more scope for design and research than boring in consolidated strata. An integral part of the usual British design is the gravel filter, which requires a finely slotted inner lining-tube to hold the gravel filter in place. The optimum velocity of the ground-water through the slots is most important; too great a velocity may cause ferrous and carbonate deposits in and around the slots, reducing the efficiency of the filter. Mr. Swales recommended a top velocity of not more than $0.2 \mathrm{ft}$. per sec; indeed an average velocity of half this figure is desirable. Adequate area of the slots is also important. An alternative to the old type of tube with slots, for example, 6 in. $\times \frac{1}{8}$ in., is a 'bridge-slotted tube' containing finer and much more numerous slots, $\left(\frac{3}{4}\right.$ in. $\times 0.03$ in.), giving about three times as much area per square foot of tube surface but usually necessitating non-corrosive materials.

The heart of Mr. Swales's communication is a disquisition on gravel packing. Originally the idea was to use comparatively coarse gravel and coarse ( $\frac{1}{8}$ in.) slots and, by some method of agitation, to draw in, through this gravel, the finer parts of the strata. The sand drawn in is replaced with gravel. A later idea was to prepare special pack material on site, and to use fine slots so that the grading curve would conform to Terzaghi's theory that, in the pack material: (a) its 15 per cent size must be at least four times as large as the 15 per cent size of the coarsest layer of formation sand; (b) its 85 per cent size must be not more than four times as large as the 85 per cent size of the finest formation sand.

This theory, though sound, was open to practical difficulties; segregation of different-sized particles was almost inevitable when placing the gravel in the borehole, so Mr. Swales successfully developed an alternative technique, based on the theory that, "The 50 per cent size of the pack shall bear a definite relationship to the 50 per cent size of the formation; and the pack shall be as uniform as possible in grain size". This relationship or ratio is known as the 'gravel pack ratio' and is usually $5 / 1$. Boreholes constructed on this principle mostly show negligible sand content in the water pumped, the amount being too small to measure. Generally an efficient gravel pack should limit the sand pumped to $0 \cdot 1$ part per million.

Practical observations on the placing of the gravel pack were given, with details from actual boreholes and the results of a flow-meter test carried out during testpumping. New photographic techniques were touched on, for the inspection of the inside surfaces of boreholes; and the treatment of limestone and chalk boreholes with acid, to clean the 'plaster' which is deposited and to open up fissures, was discussed.

So far, the artificial recharge of aquifors has not been carried out very seriously in Britain. Mr. Swales considered that much more effort should be put into research on this matter. After listing the engineering problems and desiderata, he suggested the use of a 'grout curtain' to control the area under recharge.

The director of Overseas Geological Surveys, London, Dr. S. H. Shaw, contributed the next communication, entitled "Some Aspects of Geophysical Surveying for Ground-water". In Dr. Shaw's opinion there is undoubtedly considerable scope for the further use of sub-surface methods in hydrological investigations. Although these are normally more easily applicable in well-developed countries, their particular usefulness in the early stages of development in 'new' hydrological basins (as, for example, the Chad) should not be overlooked. It is often possible to arrange for geophysical measurements to be made on boreholes at the time of their construction, whereas such measurements may be impracticable at a later stage; and the opportunity for obtaining information may therefore be lost. In surface techniques it would seem that seismic methods could be more widely utilized without undue expense. This line of investigation owes much to the oil industry for its technical development, though there is a danger that, because of lavish expenditure on it by oil companies, water engineers may receive the impression that such methods are too sophisticated and expensive to be applied to water problems.

Dr. Shaw considered that the resistivity technique is still the most generally useful of the geophysical methods in water problems, where the main object is to find a supply. One of its advantages is that empirical methods of interpretation are often satisfactory. In the past, one reason for this was that analytical methods based on comparisons of curves were hampered by the labour required to compute curves for more than a few examples of-at the most--three-layer models. Nowadays, however 
with the use of the electronic computer, four-layer curves are available. Dr. Shaw thought that this important new technique is too little appreciated, especially as the tables of potential which accompany the curves have been set out so that curves can be computed for any particular arrangement of electrodes, or for other ratios of depth and resistivity. Without advocating the abandonment of empirical interpretations where they have been successful, Dr. Shaw felt that the more sophisticated approach mentioned here might well yield more information, and even lead to useful interpretations in cases where the resistivity method had previously been thought unsuitable. "Where new tools are available", he suggested, "it is unprofitable not to explore their possibilities to the full".

Two communications then followed, on the "Applications and Limitations of Pumping Tests". The subject was subdivided into (a) engineering aspects, on which the speaker was Mr. R. J. Slater (deputy engineer and manager, Maidstone Waterworks Co., Maidstone, Kent), and (b) hydrogeological significance, which was dealt with by Dr. J. Ineson (chief geologist, Water Division, Geological Survey, South Kensington, London, S.W.7).

The layout of a well-site depends on the aquifer and on the amount of water to be abstracted; a single well may be decided on, or several small-sized boreholes. In any event, it should suit the permanent pumping plant which in turn may determine the diameter. Actual details of the costs of constructing wells of various diameters and depths, in various geological formations were included in the communication with graphs to show the constructional costs and relative quantitios of water, on a basis of well diameter. Mr. Slater referred also to the encouraging results obtained from the use of acid in chalk and limestone wells.

He also referred to the importance accorded to test pumping of trial boreholes by the Minister of Housing and Local Government under Section 5 of the Water Act, 1948, when a new source of supply from wells is contem. plated, should an objection be lodged against this proposed abstraction. In such cases, experimental work may be authorized to ascertain the presence of underground water, or its quality and quantity, subject to certain conditions, for example, the maximum quantity and duration of test pumping. For actual pumping tests, submersible pumps are an obvious choice because of their high reliability which, unfortunately, is not always matched by the diesel altemators provided on site when electricity from the National Grid is not available. Breakdowns are frequent enough to warrant a particular effort being made to obtain a Grid supply of power.

The measurement of water-levels is a vital part of pumping tests. Mr. Slater mentioned the advantages of electrical devices for manual operation, especially the electrochemical apparatus attached to a steel tape, developed by the Geological Survey. Of the automatic devices, the float-operated type is the most satisfactory. The conditions to be observed during pumping tests were given in some detail, and are obviously the result of considerable practical experience. The test normally should be carried out after all 'development work' on the well is finished; and before the actual tests, the well should be rested for at least as long as any pumping necessary for the development of the well. Usually a 'step drawdown' test is carried out; some three or four steps being sufficient, at or near equilibrium conditions, to give the yield characteristics of the well. Such information may take a week or ten days to obtain. The frequency and duration of observations must be decided by experience and may vary from once to several times a day.

Care is needed in the disposal of water pumped during testing, to ensure that it is not recirculated; discharge into water-courses must be notified to river, catchment, or navigation authorities; and the water must be as clean and non-injurious as is reasonably possible. Eventually, the plotting of abstraction rates and water-levels on a time base can be carried out. Mr. Slater warned that the "plotting of time-drawdown and distance-drawdown curves should not be done on site, unless the engineer is very familiar with their interpretation and analysis". Finally, he pointed out the usefulness of pumping tests on existing wells when the question of increasing, or even maintaining, the yields from existing sources arose.

Dr. Ineson, dealing with the hydrogeological significance of pumping tests, observed that, since the ground-water province is within the ambit of three-dimensional geology, a complete understanding of geological analysis and interpretation is essential. Information is needed also on the fluid properties and dynamies of ground-water as it percolates through, and discharges from, an aquifer. $\mathrm{H}_{\Theta}$ regarded pumping tests on existing wells, and on new wells, as a valuable means for obtaining hydrogeological information, especially in regard to the yield-characteristics and potential of a well, the hydraulic properties of aquifers, and the effect of permanent abstraction. The most important hydraulic properties of an aquifer are hydraulic conductivity (rate of flow through unit cross-sectional area of the aquifer under a fixed hydraulic gradient and at a fixed temperature); the transmissibility (rate of flow through a vertical strip of given width, extending the full thickness of the aquifer, under a fixed hydraulic gradient and at a fixed temperature); and the coefficient of storage (ratio of volume of water derived from storage from a vertical column on a base of unit area, extending the full thickness of the aquifer, during a reduction in head equivalent to unit fall in water-level, to unit volume of that aquifer).

As water-levels fall round a well when the pumping rate is raised, the shape of the solid generated by this fall is known as the cone of depression. The lower the transmissibility, the steeper the cone. The shape and size of the cone depend also on the hydraulic properties of the aquifer. Ground-water flow around a well, under various geological conditions, can be expressed by mathematical equations based on models simulating aquifer conditions. Although certain assumptions have to be made, in regard to the homogeneity of the aquifer, and its extent and transmissibility, and to the penetration of the discharging well to the full extent of the aquifer, it is possible, for laminar flow under steady-state conditions, to apply these equations successfully to natural conditions. The hydraulic properties of the aquifer are obtained from pumping tests. These parameters depend on fundamental geological properties, determined during sedimentation but modified by secondary geological processes such as faulting, folding and fissuring, and by secondary chemical precipitation. Geological studies therefore are vital in assessing aquifer permeability.

Dr. Ineson then commented in detail on the results of individual pumping tests carried out since 1948 by the Water Department of the Geological Survey. Of some 200 tests, the majority were conducted on wells in the Chalk, the most important aquifer in Britain, which produces about 40 per cent of the ground-water abstracted. His observations were especially interesting in that they explained what happens when deviations occur from the conditions assumed for the mathematical equations already mentioned. Like Mr. Slater, Dr. Ineson referred to the use of step draw-down tests for obtaining hydrogeological information. 'Yield-depression' curves are obtained by plotting rates of abstractions against drawdown in water-level. Wells in a single aquifor appear to be characterized by a definite family of such curves, and it has been found that the form of these curves is related statistically to the transmissibility. Finally, Dr. Ineson discussed the need for information on the boundaries of aquifers, and illustrated their effect on ground-water flow. A river crossing an aquifer and replenishing it constantly is taken as an example, and the equivalent hydraulic system, including the effect on the cone of depression, is developed with great skill and clarity. 
The concluding communication, entitled "The Use of Ana. logue Computers for Studies in Ground-water Hydrology", was contributed by Mr. H. E. Skibitzke, who is mathematician at Water Resources Division, U.S. Geological Survey, Phoenix, Arizona. The Division has applied computer techniques to many of the problems encountered in its operations.

Digital computers are used in the surface-water measurement programme, and in soil-moisture and evaporation studies. Water-level data in rivers, too, have been collected on digital tapes ; such records can be processed quickly, without elaborate programming. In addition, an analogue computing programme has been developed since 1954, when it was originally applied to groundwater systems. About three years ago an operational analogue model unit was established, to apply geological and hydrological information-already available from data-collecting programmes - to a community's water problems. The ground-water computing systems are of the direct analogue type, using the relationship between Darcy's law and Maxwell equations. The analogies between electrical resistance and permeability times a distance, also between electrical capacitance and storage coefficient times a volume, provide the basis. Models are constructed, similar to large-scale maps, which contain, in scale, a physical description of the relating function.

Mr. Skibitzke showed, by mathematical reasoning, how to derive an expression for the rate of release of liquid from a given volume as hydraulic head is changing with time ; this equation is then used in determining an elec. trical analogy, using an expression for the electrical current flowing into a junction of an electrical network. Electrical analogies are then given for head, storage coefficient, and permeability. Head is analogous to electrical potential; storage coefficient times the finite volume of the aquifer is diroctly analogous to electrical capacitance; days in the aquifer are proportional to a few microseconds on an oscillograph scroen connectod to the analogue model.

In the model constructed on these analogies, the electrical resistors are made proportional to the hydraulic resistance of the aquifor in directions parallel to the three co-ordinate axes. The directions of the axes are the same for the models. The networks are chosen to represent, in scale, a small element of the aquifer, the centre of an element in the aquifer being represented by the centre of a junction of a resistor network. An electrical capacitor proportional to the storage coefficient is connected from this junction to the ground. By a generalized application of mathematical equations given in the communication, varia tions in hydraulic permeability can be accounted for by varying the electrical resistance. Boundary-condition problems can be studied by arranging for an electrical current flow-system, that is quantitatively proportional to the hydraulic flow system, to pass into and out of the model. Mr. Skibitzke discussed also the importance of choice of scale as between the actual aquifer and the electrical simulation of conditions in the model. The quantities of electrical current put into the model can be chosen so that space, time, quantity, and head will appear with a known figure of proportionality. The effects of recharge from rainfall or rivers and other kindred conditions can be studied in their variations over very long periods of time. Quantitative data are 'removed' from the model by an oscilloscope which indicates, in microseconds, the change in eloctrical potential, as a function of time, at its input terminals.

After describing the practical operation of the computer, Mr. Skibitzko referred to future developments. Almost any conceivable hydrological system can be studied by computer methods, though in some cases the cost would be prohibitive. Present research work is aimed at reducing the constructional cost of models and at simplifying the electronic linkages that are needed to describe boundary conditions. Finally, Mr. Skibitzke refered to some highly complex hydrological conditions, not amenable to rigorous mathematical analysis, in which computations of groundwater flow parameters have led to greatly increased understanding of what is actually occurring in aquifers. In particular, he mentioned the effect of the ovaporative process that seems to occur ovor all shallow water-tables. In fields such as this, developments in analogue computing have helped substantially in both the theoretioal and the practical analysis of a hydrological problem. A film was shown illustrating the analogue installation at Phoenix, Arizona, on which Mr. Skibitzke and his colleagues had been working.
W. O. SKEAT

\section{PROTEINS AND CRYSTALLOGRAPHY}

$\mathrm{T}$ HE award of tho 1962 Nobel Prizes for Medicine and Chemistry to Dr. F. H. C. Crick, Prof. W. Watson and Prof. M. H. F. Wilkins, for their work on the structuro of nucleic acids, and to Dr. J. C. Kendrew and Dr. M. F. Perutz, for their analyses of protein structuros, has directed attention to the outstandingly fruitful contribution made by X-ray crystallography to our knowledge of biologically important molecules. The international symposium on "Protein Structure and Crystallography", held at the University of Madras during January 14-18, was, therefore, particularly well timed. In effect there were two symposia, with sessions hold on alternato days, at which recent work on protein structures and the developments of X-ray erystallography were discussed. But the two subjects inevitably overlappod in the discussions of the X-ray mothod appliod to molecular struc. ture analysis at which exponents of different techniques were brought logether and hence helped to assoss the significance of each other's results.

The symposium was organized by Prof. G. N. Ramachandran and his staff, with the support of the University of Madras, the Indian Council of Scientific and Industrinl Research, the Indien University Grant Commission and other Government and private ageneies. Sir A. L. Mudaliar, vice-chancellor of the University, welcomed the dolegates and Sir C. V. Raman gave an inaugural address on "Crystal Structure and Crystal Behaviour". The sessions were opened by Prof. M. S. Thacker.

The President of the symposium was Sir Lawrence Bragg (United Kingdom), whose address was read, in his absence through illness, by Prof. Ramæchandran. He describod the devolopment of $\mathrm{X}$-ray structure analysis as applied to complex molecules, mentioning the PaulingCorey $\alpha$-helix, the Watson-Crick double helix for deoxyribonucloic acid (DNA) and the Ramachandran triple helix for collagen as the main achievements of the indirect approach, and the analyses of vitamin $B_{12}$ and of the proteins hrmoglobin and myglobin as triumphs of the single-crystal method.

The X-ray analysis of globular protein structures was described in more detail by Prof. D. Harker (United States), who announced the latest results of his work on ribonuclease, and by Dr. D. C. Phillips (United Kingdom), who outlined tho recent dovolopments of work on hæmoglobin and myoglobin and a number of other proteins, including lysozyme, $\alpha$-chymotrypsin and $\beta$-lactoglobulin. 